\title{
Escolarização e trabalho de beneficiárias do Bolsa Família: estudo de caso em Ribeirão da Neves - MG
}

\author{
Schooling and work of beneficiaries of the Bolsa Familia: case study in Ribeirão da Neves - \\ $M G$
}

\section{Amanda do Carmo Amorim Nadú* Ana Cláudia Ferreira Godinho**}

\section{Resumo}

Neste artigo, tem-se como objetivo, discutir a partir de experiências de escolarização e de trabalho de beneficiárias do Programa Bolsa Família (PBF), do município de Ribeirão das Neves, em Minas Gerais, como o Programa se apresenta enquanto porta de entrada para o acesso ao direito à educação e ao trabalho para as beneficiárias. Por meio de uma abordagem qualitativa, foi escrito a partir da análise do conteúdo de 12 entrevistas semiestruturadas de beneficiárias do PBF de um Centro de Referência de Assistência Social (CRAS) do município; entrevista realizada com a coordenadora da unidade em diálogo com estudos do campo da Educação Popular, Trabalho e Gênero e das contribuições de autores que refletem sobre o PBF. Pode-se concluir que as entrevistadas possuem experiências marcadas pela negação do direito de se escolarizarem e experiências de trabalhos precários. Apesar do PBF se mostrar como um importante programa social no que concerne ao alívio imediato da pobreza entre as entrevistadas, o Programa apresenta restrições consideráveis no que tange ao acesso ao direito à educação e ao trabalho por essas mulheres, entre elas, a não articulação com as demais políticas públicas disponíveis no município.

Palavras-chave: Programa Bolsa Família. Educação. Trabalho. Beneficiárias.

\section{ABSTRACT}

In this article, the objective is to discuss the experiences of schooling and work of beneficiaries of the Bolsa Familia Program (PBF), in the municipality of Ribeirão das Neves, in Minas Gerais, as the Program presents itself as a gateway to access to the right to education and work for beneficiaries. Through a qualitative approach, it was written based on the content analysis of 12 semi-structured interviews with beneficiaries of the PBF of a Reference Center for Social Assistance (CRAS) in the municipality; interview with the unit coordinator in dialogue with studies in the field of Popular Education, Labor and Gender and the contributions of authors who reflect on the PBF. It can be concluded that the interviewees have experiences marked by the denial of the right to school and experiences of precarious work. Although the PBF is shown to be an important social program with regard to the immediate alleviation of poverty among the interviewees, the Program presents considerable restrictions with regard to access to the right to education and work for these women, among them, the lack of articulation with other public policies available in the municipality.

Keywords: Bolsa Família Program. Education. Job. Beneficiaries.

\footnotetext{
* Mestrado em Educação e Formação Humana, pela Faculdade de Educação da Universidade do Estado de Minas Gerais (UEMG). Especialista em Gestão em Saúde Pública, pela Pontifícia Universidade Católica de Minas Gerais (PUC MINAS).

** Doutora e Mestre em Educação pela Universidade do Vale do Rio dos Sinos - UNISINOS. Pós-doutora em Educação pela Universidade Federal Fluminense. Professora adjunta da Universidade Federal do Rio Grande do Sul - UFRGS. Professora colaboradora do Programa de Pós-Graduação em Educação da Universidade do Estado de Minas Gerais - PPGE-FaE-UEMG.
} 


\section{Introdução}

No âmbito de uma sociedade de economia capitalista, marcada pela exploração do trabalho e pelas desigualdades, onde existe uma classe "naturalmente" desigual e excluída dos direitos, o Estado é solicitado para redefinir funções e pressionado a atuar de forma positiva, buscando promover a diminuição das desigualdades por meio da ordenação dos direitos socais, entre eles, o direito à educação e ao trabalho. O acesso a tais direitos é mediado pelas políticas públicas, as quais tem por objetivo, sobretudo, intervir e transformar uma realidade social onde os sujeitos estão tendo seus direitos violados.

Nessa perspectiva, o Programa Bolsa Família (PBF) criado em 2003 pelo Governo Federal, e instituído pela Lei no 10.836 , de 9 de janeiro de 2004, encontra-se no bojo das políticas públicas e ocupa uma posição central na Política Nacional de Assistência Social (PNAS) e de proteção social ampla, visando o combate e o enfretamento da pobreza no Brasil, o que implica em ações conjuntas das diferentes áreas determinantes das condições de vida, uma vez que a pobreza possui um caráter pluridimensional. A partir de uma Transferência de Renda Condicionada (PTCR) as famílias elegíveis ${ }^{1}$ têm acesso a uma renda monetária, a qual depende do cumprimento de condicionalidades nas áreas da educação e da saúde.

A política do Programa pretende combater a pobreza por meio de duas frentes principais. O enfrentamento às desigualdades por meio da transferência de um benefício financeiro, associado à garantia do acesso aos direitos sociais básicos (saúde, educação, assistência social e segurança alimentar), o que se configura num dos principais objetivos do PBF e a inclusão social, contribuindo para a emancipação das famílias beneficiadas, construindo meios e condições para que elas possam sair da situação de vulnerabilidade que se encontram (SILVA; LIMA, 2010).

Para tanto, o PBF é constituído por dois eixos configuradores dentro da sua proposta: os benefícios monetários, que contemplam as transferências de recursos financeiros e os não monetários, que são representados pelas ações e programas complementares ${ }^{2}$ voltados para

\footnotetext{
${ }^{1} \mathrm{O}$ critério de elegibilidade do PBF é fundamentalmente baseado na renda familiar per capita, sendo essa norma primária para seleção das futuras famílias beneficiárias (SAGI, 2019).

${ }^{2}$ No caso dos adultos, uma das ações complementares do PBF se efetiva por meio da intersetorialidade, como por exemplo, via Programa Nacional de Acesso ao Ensino Técnico e Emprego (PRONATEC) que integra o Plano Brasil Sem Miséria (BSM). Com o objetivo de ampliar a oferta de educação profissional e tecnológica via programas, projetos e ações de assistência técnica e financeira na modalidade de Formação Inicial e
} 
a superação da situação de vulnerabilidade das famílias, o que inclui a educação, a inserção no mercado de trabalho, entre outros (SILVA, 2016).

Como em outros programas com proposta de inclusão social, o PBF tem como cerne a família, a qual, em grande parte, tem a mulher como responsável prioritária, "é uma figura feminina - a mãe, principalmente - que frequentemente assume o papel de mediadora entre - Estado e a família, responsabilizando-se pela execução das orientações recebidas pelos trabalhadores sociais" (SANTOS, 2014, p.482). Nesse contexto, conforme dispõe o Art. 23 do Decreto no 5.209 de 2004, “O titular do cartão de recebimento do benefício será preferencialmente a mulher ou, na sua ausência ou impedimento, outro responsável pela unidade familiar" (BRASIL, 2004). A Lei 10.836/04 dispõe no Art. $2^{\circ}$, parágrafo 14, que "o pagamento dos benefícios previstos nesta Lei será feito preferencialmente à mulher, na forma do regulamento". Nessa mesma direção, o Manual do Pesquisador - Programa Bolsa Família (2018) dispõe que:

[...] o Bolsa Família realiza o pagamento dos benefícios preferencialmente às mulheres, com objetivo de contribuir para a ampliação do bem-estar da família e, ao mesmo tempo, da autonomia feminina no espaço doméstico e nas comunidades locais (p.10).

As mulheres são priorizadas como corresponsáveis pelo seu andamento do PBF e, em 93\% dos casos, são elas as receptoras diretas da renda monetária (SAGI, 2019). Embora não tenha sido idealizado para que houvesse um processo de mudanças na vida das beneficiárias, a escolha das mesmas como a pessoa de preferência para administrar o benefício financeiro acaba por conduzir que as questões relativas à vida privada e pública dessas mulheres se tornem transversal no Programa. Adicionalmente, como aponta Falquet $(2016$, p.45) é necessário que as mulheres não "privilegiadas por 'raça' e 'classe' " sejam consideradas.

Apesar da centralidade na figura da mulher como responsável por gerir o benefício e de estudos apontarem mudanças significativas na vida das beneficiárias em relação a uma programação da própria vida (REGO e PINZANI, 2013), com maior exercício de poder, ainda que esse seja sempre direcionado ao consumo das necessidades essenciais no contexto familiar após se tornarem beneficiárias (CARLOTO e MARIANO, 2012), pouco se discute sobre as reais condições de vida dessas mulheres em relação à educação e o trabalho.

Continuada (FIC), para pessoas inscritas ou em processo de inclusão no Cadúnico, com prioridade para os beneficiários do PBF e do BPC (MDS, 2015). 
Nesse sentido, olhar para as experiências de escolarização das beneficiárias é relevante para compreender o que a política de proteção social do PBF tem a dizer para políticas públicas da educação voltadas para a elevação de escolaridade das mulheres, como por exemplo, a Educação de Jovens e Adultos (EJA). Por conseguinte, a escolaridade é um elemento importante na definição dos tipos de ocupação que as mulheres beneficiárias do PBF têm acesso e, portanto, pode contribuir para tirá-las ou não da condição de extrema pobreza.

Assim, este estudo busca discutir por meio de resultados da dissertação de mestrado em Educação e Formação Humana, intitulada "Experiências de escolarização e de trabalho de beneficiárias do Programa Bolsa Família", defendida em julho de 2019, como o PBF se apresenta para beneficiárias do Programa do município de Ribeirão das Neves, Minas Gerais, enquanto porta de entrada para o acesso ao direito à educação e ao trabalho.

A partir de uma pesquisa qualitativa, segundo Chizotti (1998) e Minayo (2002), tal como proposto por Lüdke e André (1986) adotamos o estudo de caso, considerando que o método permite que algo singular seja analisado e interpretado, a fim de abarcar toda a realidade. Os dados são provenientes de 12 entrevistas semiestruturadas com beneficiárias do PBF referenciadas em um Centro de Referência de Assistência Social (CRAS) em Ribeirão das Neves, MG e, também, de uma entrevista realizada com a coordenadora da unidade.

O roteiro das entrevistas semiestruturadas, era composto de duas seções: (Educação/Escolarização) e (PBF e Trabalho). Para a realização das entrevistas, durante os meses de abril, agosto, setembro e outubro de 2018, optamos pelas estratégias aleatórias convidando as beneficiárias que compareciam no CRAS e se dispuseram a realizar a entrevista. Foram consideradas a participarem do estudo, apenas as mulheres que recebiam o benefício com o tempo mínimo de um ano.

O tratamento dos dados foi realizado na perspectiva da análise de conteúdo de Bardin (2011), considerando para além do que está simplesmente dito ou descrito, contemplando interpretações mais profundas para interpretar e validar, a partir da fundamentação teórica norteadora do estudo, o conteúdo presente nas entrevistas.

\section{O PBF em Ribeirão das Neves e o perfil das entrevistadas}


Com base nos dados do Censo 2010, Ribeirão das Neves apresenta uma população estimada de 328.871 habitantes, e segundo o Instituto Brasileiro de Geografia e Estatística (IBGE) do ano de 2017, o município possui 10.315 pessoas em extrema pobreza e ostenta um dos piores índices educacionais da região metropolitana de Belo Horizonte, situando-se entre os últimos nas questões relativas à renda.

Em relação a formação socioespacial de Ribeirão das Neves, Silva (2016) descreve a constituição do município como segregada, instituída a partir de um grande agrupamento de pessoas com baixa renda, com ausência de uma estrutura econômica, a qual pudesse oferecer trabalho para a população e com ínfima infraestrutura urbana e de serviços públicos. "A expansão periférica baseada em loteamentos destinados a população menos favorecida juntamente com a presença dos presídios proporcionou um cenário de baixos índices e indicadores socioeconômicos" (SILVA, 2016, p.78).

Considerada "cidade presídio", Ribeirão das Neves possui oito estabelecimentos prisionais, o que contribui para o parco investimento em atividades industriais ou de produção tecnológica. Soma-se a isso, a questão do estigma negativo devido aos consideráveis casos de violência e criminalidade recorrentes no munícipio São muitas as desigualdades sociais presentes, justificando também, a escolha do mesmo como o campo empírico de estudo.

As políticas públicas disponíveis no território são de difícil acesso e o PBF é apontado como uma das principais políticas públicas do município. Os parcos investimentos locais, a inexistente ou insatisfatória oferta de equipamentos públicos das áreas de saúde, assistência social e educação, "se configura como um conjunto de graves impedimentos para que a população possa usufruir dos direitos sociais ditos como universais" (FRANÇA, 2016, p.114115).

De acordo com o Relatório de Programas e Ações do Ministério do Desenvolvimento Social (MDS) do ano de 2018, a Rede Socioassistencial do Sistema Único de Assistência Social (SUAS) em Ribeirão das Neves, é composta por sete unidades do CRAS, um Centro de Referência Especializado de Assistência Social (CREAS) e dez Unidades de Acolhimento. O PBF beneficiou, no mês de junho de 2019, 15.479 famílias, representando uma cobertura de 87,8\% da estimativa de famílias pobres no município (SAGI, 2019).

Especificamente sobre o PBF no CRAS onde o estudo foi desenvolvido, o equipamento possui uma única equipe para atuar em todos os serviços ofertados. Nesse 
sentido, um dos dificultadores existentes diz respeito à redução da equipe, especialmente pensando que a unidade executa três serviços importantes no âmbito da proteção social básica, o Cadastro Único para Programas Sociais do Governo Federal (Cadúnico), o Serviço de Proteção e Atendimento Integral à Família (PAIF) e o Serviço de Convivência e Fortalecimento de Vínculos (SCFV).

No que diz respeito ao número de beneficiárias do PBF referenciadas no CRAS em questão, o acesso ao banco de dados obtido junto aos Relatórios Gerenciais do Cadastro Único (RELCAD), atualizados em 11 de outubro de 2017, mostrou o total de 3.364 registros de beneficiárias referências do núcleo familiar acompanhadas pela unidade e dispersas nos diversos 40 bairros de abrangência de seu território.

Para obter o perfil das 12 beneficiárias do PBF entrevistadas, por meio de variáveis relativas às beneficiárias do PBF, traçamos as características sociodemográficas das participantes. Em relação à idade, quase metade das beneficiárias, $41,66 \%$ possuíam na época das entrevistas, mais de 40 anos. Quanto à escolaridade, 8,33\% das beneficiárias possuíam de zero a quatro anos de estudo; $58,33 \%$ de cinco a oito anos e $33,33 \%$ de nove a onze anos de estudo. Assim como em outras pesquisas que envolvem a população do PBF, a baixa escolaridade é uma característica marcante das beneficiárias do Programa.

A grande maioria das beneficiárias, mais de $80 \%$, se declarou preta ou parda, o que de certa forma, representa a população que integra o Programa. No que concerne à profissão, $41,66 \%$ das beneficiárias se declararam do lar, seguida da profissão de cuidadora de idosos, 16,33\%; auxiliar de serviços gerais, diarista ou domésticas, representando cada uma, 8,33\%. Sobre a situação conjugal, a maior parte das entrevistadas era casada ou estavam em uma união estável, 58\%. No que tange ao número de filhos, mais da metade delas possuía, no momento da pesquisa, um ou dois filhos, $58 \%$. Quanto ao tempo de benefício, 33,33\% das entrevistadas recebiam o valor monetário entre um e dois anos; $41,67 \%$ entre três e quatro anos; $16,67 \%$, entre cinco e sete anos; $8,33 \%$ sete anos ou mais. A seguir, discutimos alguns resultados da pesquisa, neles as entrevistadas são identificadas por meio de nomes fictícios.

\section{Experiências de escolarização das beneficiárias}

Direcionar o olhar para as experiências de escolarização das beneficiárias responsáveis por gerir o benefício do PBF é especialmente significativo quando consideramos 
as palavras de Rosemberg $(2013$, p.333) que "a educação das mulheres é fato recente e intenso", contumaz para as mulheres beneficiárias, as quais representam um contingente de pessoas que vivem em condições socialmente vulneráveis.

Num contexto mais amplo, essa realidade é compreendida por Gentili (2009) como um sistema educacional "universal sem direitos", o qual tem como agravante à associação entre a pobreza e a desigualdade vivida por um número considerável de pessoas, que na maioria das vezes têm uma entrada prematura no mercado de trabalho, sofre com uma deficiente nutrição e com condições adversas de saúde, vivencia uma gravidez precoce, no caso das meninas, entre outros. Esses são fatores que associados ou não, dificultam a entrada ou permanência das pessoas expostas a uma maior condição de vulnerabilidade social nas instituições escolares e assim, também, da democratização do direito à educação.

Um ponto importante referente à escolaridade das beneficiárias, é que apenas duas entrevistadas concluíram o ensino médio, e não o fizeram por meio da escola regular, e sim por intermédio de programas governamentais, o Centro Estadual de Educação Continuada (CESEC) e o Exame Nacional para Certificação de Competências de Jovens e Adultos (ENCCEJA).

De maneira geral, as experiências de escolarização das entrevistadas mostram que os percursos escolares dessas mulheres são profundamente marcados pelas desigualdades e antagonismos presentes na sociedade. E, também, perpassa pela questão das escolhas dos projetos pessoais, a saber "a ausência de educação em sentido amplo [...] marca profundamente a qualidade de vida das pessoas" (REGO; PINZANI, 2013, p.173), como apontam os relatos a seguir:

Quer dizer, eu estudei enquanto teve o grau de estudo lá eu estudei. Porque lá, a gente repetia o ano, porque não tinha mais grau. $O$ último grau que tinha nessa escola lá, era a 4aㅡ série (Ana, 54 anos, 3a série, beneficiária desde 2009).

Quando chegava na 5a série tinha que comprar os livros e algumas coisas que os professores pediam de contribuição, a gente tinha que dar [...] na época meu pai achava um absurdo, porque tinha que comprar alguns livros. Aí, ele não queria, e eu peguei, como eu era menor de idade, eu dependia dele, do dinheiro dele, parei de estudar (Clara, 65 anos, 4ạ série, beneficiária desde 2017).

Eu parei também porque eu arrumei filho. Eu arrumei filho com 15 anos (Filomena, 31 anos, 7ạ série, beneficiária desde 2015).

São experiências que nos mostram como a imposição coerciva da realidade socioeconômica afeta de maneira negativa as beneficiárias do PBF. Corroborando com Gentili (2009), as experiências relatadas evidenciaram como, ao longo de suas vidas, a oferta da 
educação para essas mulheres não considerou as particularidades e se fez a partir da segregação e exclusão. Ademais, os relatos dão conta de aspectos sobre seus percursos escolares e expõem como o fato de terem parado de estudar, ou terem interrompido seus estudos, refletiram em várias fases de suas vidas:

Hoje eu penso que eu devia ter estudado, ter aprendido alguma coisa, porque tudo que eu preciso tenho que pedir, pedir para os outros lerem, número eu não sei. No mercado eu não sei ver nada de conta, nada. Quem vai receber para mim é o meu marido. Tem vez que ele vai comigo. Ele passou a senha para mim, para eu aprender, para eu me acostumar, mas, mesmo assim, eu não consigo, chego lá e esqueço. Tenho medo de esquecer, aí não vou, aí ele vai. Eu esqueço, não sei mexer com esse negócio de número e receber não (Nágela, 44 anos, analfabeta, beneficiária desde 2003).

Para você às vezes preencher um texto, preencher um currículo, eu misturo, troco muito as palavras. Isso tudo por quê? Por causa do estudo. Eu não tive a oportunidade de estar desenvolvendo nessa parte. Uma vez eu fui fazer uma entrevista preenchi aquele cadastro [...]. Só que lá eu senti falta na hora de preencher o currículo [...]. Às vezes tinha hora que eu atendia ao telefone e era recado para o patrão, eu escrevia os bilhetes não sei quantas vezes, achava que estava escrevendo errado (Ana, 54 anos, 3ª série, beneficiária desde 2009).

No âmbito do estudo foi possível observar a existência de um consenso a respeito da relevância da escolaridade na vida dos sujeitos. Os extratos das falas apresentados ilustram como a maioria das entrevistadas avalia o papel da escolaridade nas suas vidas e apontam a escolaridade como fundamental para melhorar a qualidade de vida das pessoas. Além disso, os relatos apontam que a falta de trabalho, ou de um trabalho mais qualificado, é a consequência do abandono escolar que mais afeta suas vidas. Como assinala Saviani (2011, p.11), "dizer, pois, que a educação é um fenômeno próprio dos seres humanos significa afirmar que ela é, ao mesmo tempo, uma exigência do e para o processo de trabalho, bem como é, ela própria, um processo de trabalho". Como nos relatos a seguir:

A pessoa com estudo ela tem mais opção. Opção de trabalho, opção de tudo, para tudo (Celina, 48 anos, 4aㅗ série, beneficiária desde 2017).

O estudo faz muita falta, até mesmo para o emprego. Você consegue o emprego, e você não tem escolaridade, você não consegue [...] ah, tinha conseguido um

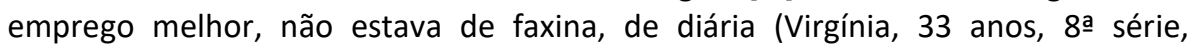
beneficiária desde 2009).

As falas demostram, também, que durante a vida adulta, a decisão por estudar é permeada por importantes dificuldades, as quais têm relação com a "especificidade desses tempos da vida - juventude e vida adulta - e da especificidade dos sujeitos concretos históricos que vivenciam esses tempos" (ARROYO, 2005, p.22). O desejo de prosseguir com os estudos 
vem sempre acompanhado por algum obstáculo, dentre eles os que perpassam as questões de gênero:

[...] eu fiz até a matrícula, mas eu não fui não. Igual meu menino, não tem ninguém para ficar com ele. $O$ homem não quer ficar com a criança, porque geralmente homem hoje em dia não ajuda a gente direito, então não dá (Andréa, 30 anos, 4ạ série, beneficiária desde 2007).

São experiências que nos levam a ponderar sobre as necessidades das beneficiárias em relação ao direito de se escolarizarem, as quais não podem ser compreendidas apenas no que concerne às situações de pobreza. É necessário considerar a condição de dominação que atravessa as suas vidas, pois "a sujeição feminina é diferente da sujeição de outros indivíduos e classes" (REGO; PINZANI, 2013, p.50).

Os resultados mostram que $66,6 \%$ das beneficiárias manifestam a vontade de retomar os estudos. Nessa direção, a EJA se configura um importante meio para que esse retorno se materialize, pois tal modalidade permite que sejam compreendidas "como sujeitos sociais, culturais, vivenciando tempos da vida sobre os quais incidem de maneira peculiar, o desemprego e a falta de horizontes; como vítimas da violência e do extermínio e das múltiplas facetas da opressão e exclusão social" (ARROYO, 2005, p.24).

No contexto analisado, no entanto, as poucas experiências das beneficiárias na EJA apontam que, tal modalidade ainda necessita ser melhor direcionada. Nenhuma beneficiária relata ter tomado conhecimento sobre a EJA por meio do PBF e do CRAS, evidenciando a necessidade de ampliação e articulação entre as políticas públicas.

Já ouvi falar da EJA, mas não aqui. Eu sei que tem a EJA lá em $\mathrm{BH},[\ldots]$ tem uma colega minha que faz, ela mora lá. Aqui em Neves eu não sei (Clara, 65 anos, 4ạ série, beneficiária desde 2017).

Minha menina que me falou, e estava mostrando na televisão (Ana, 54 anos, 4a série, beneficiária desde 2009).

Assim, considerando que o Cadúnico contempla informações relativas a escolarização dos titulares do PBF, o mesmo possibilitaria uma articulação entre as políticas de assistência social e de educação como um meio para se alcançar as beneficiárias não escolarizadas inscritas no Programa. Como argumentam Bartholo, Passos e Fontoura (2017, p.14) "é viável que as informações do Cadastro Único sejam utilizadas para priorizar e 
monitorar o acesso das beneficiárias do PBF, ou de todas as mulheres cadastradas, a serviços, programas e benefícios públicos".

Diante disso, apreendemos que mesmo sendo consenso que a educação é condição moral para todos os sujeitos na construção de uma sociedade mais equitativa, a educação como direito ainda se constitui um desafio, especialmente para as mulheres que se encontram nos estratos mais vulneráveis da sociedade.

Frente ao pressuposto de que o PBF, por meio dos benefícios não monetários tem como objetivo contemplar as famílias para além apenas das questões de subsistência, podemos argumentar a partir das experiências de escolarização das entrevistadas que mesmo depois de se tornarem beneficiárias, o direito ao acesso à educação continua sendo negado a essas mulheres. Ademais, o cenário de vulnerabilidade do município de Ribeirão das Neves, alinhado a pouca interlocução das políticas públicas existentes, mais especificamente entre a política de assistência social e de educação, colaboram para a manutenção de status de não direitos experimentados e privações em relação à educação por esse grupo de mulheres analisado.

\section{Experiências de trabalho das beneficiárias}

As beneficiárias do PBF entrevistadas são unânimes em relacionar uma maior escolarização a um trabalho mais digno, ou melhor remunerado, e trazem por meio de seus relatos, experiências comuns de trabalhos, dentre as quais se destacam o trabalho como doméstica, diarista e cuidadora de idosos, em sua grande maioria experiências marcadas pela violação dos direitos trabalhistas.

Destaca-se que dentre as 12 entrevistadas, apenas duas beneficiárias relatam nunca terem tido nenhuma experiência de trabalho, as demais mulheres tiveram em algum momento de suas vidas, a oportunidade de trabalhar fora de casa. Sobre isso, dentro de uma perspectiva de gênero, Hirata (2009) afirma que o aumento da participação feminina no mercado de trabalho é correlato à precarização e a vulnerabilidade, tanto para o setor formal, quanto para o informal.

Ainda na perspectiva da autora, as experiências perquiridas neste estudo, apontam que o acesso das beneficiárias ao mercado de trabalho se mostrou limitado às necessidades dessas mulheres, a dimensão de dominação facilmente percebida e a associação entre sexo, 
classe e raça. Mesmo que as entrevistadas já tenham se inserido no mercado de trabalho, em alguma fase de suas vidas, tal inserção tem relação direta com a persistência das desigualdades, dos antagonismos e das violações de direitos:

Na verdade eu trabalho pesado, limpeza. Eu já trabalhei e cuidei muito de idoso, mas não de carteira. Eu trabalhei muito já na minha vida, mas era faxina mesmo, diária. Olha, eu com 14 anos, eu já dormia no emprego porque eu já olhava uma criancinha, mas não era fichado [...] trabalhei muito de diarista. Na verdade, agora eu estava era panfletando, eu não tenho vergonha, estava panfletando porque não estava tendo nada para fazer e não momento não está tendo nada mesmo (Virgínia, 33 anos, 8a série, beneficiária desde 2009).

Trabalhei muitos anos em casa de família, desde os 16 anos de idade. Comecei olhando crianças, depois em casa de família mesmo, lavando, passando, cozinhando, comecei nova (Clara, 65 anos, 4a série, beneficiária desde 2017).

Ademais, com o direito ao acesso à educação negado, uma das consequências é a negação do direito ao trabalho digno, ou o acesso a um trabalho precarizado:

\begin{abstract}
Eu estava correndo atrás até assim, na prefeitura, esse pessoal que varre rua, essas meninas que ficam varrendo rua, para ver se eu consigo um emprego para mim. Já fui lá e levei currículo, carta. Deixei lá, estou esperando para ver se consigo. Sei lá, minha vontade é de... Já procurei tantos serviços. Assim, porque casa de família para mim também não vai dar, tem que fazer as coisas, tem casa que eles deixam os negócios escritos para a gente fazer e eu não sei ler. Pessoal fala: Cuida de idoso. Mas, também, tem que dar os remédios e lê tudo direitinho, horário, e eu não sei. Mercado, esses negócios, tudo para mim não dá (Nágela, 44 anos, analfabeta, beneficiária desde 2003).
\end{abstract}

Esta fala, em especial, evidencia como a ausência de escolaridade impossibilita que a entrevistada faça mínimas escolhas para sua vida. Diferente das demais mulheres, as quais possuem algum grau de escolarização e podem pelo menos optar por um emprego de serviços, o chamado, "serviço pessoal", designado por Hirata (2001, p.149) como "trabalho doméstico remunerado, guarda de idosos e crianças, etc", a única opção de trabalho que a beneficiária Nágela consegue enxergar para si, é o de varrer as ruas da cidade, por acreditar que esse trabalho não exigirá dela nenhum tipo de leitura.

Concomitantemente, no âmbito do trabalho doméstico remunerado, estruturado na divisão sexual do trabalho doméstico, se perpetuam nas atividades de trabalho realizadas no espaço público, as atividades realizadas no contexto de vida privada das entrevistadas. Tais situações estão inscritas nas relações sociais construídas entre os sexos, como apontam 
Kergoat (1997) e Hirata (2009). Os relatos das experiências de trabalho comprovam que grande parte dessas beneficiárias reproduz na esfera pública, trabalhos similares ao realizado no espaço privado do lar, como na fala seguinte:

Porque a faxina ela é pesada, em certos lugares, em certas ocasiões o que você vai fazer é pesado. Mas, a gente fala que não é pesado para mulher, porque a mulher parece que ela já nasceu para aquilo, com diz o ditado popular "a mulher nasceu para aquilo", mas, não tem como falar que não é pesado e puxado, porque é. Mas, vai indo a gente acostuma com aquele ritmo (Cecília, 38 anos, 4aㅗ série, beneficiária desde 2011).

Para além da condição de vulnerabilidade social e da baixa escolaridade, as quais são determinantes para que as beneficiárias se submetam a trabalhos precários, há de se considerar na fala da entrevistada Cecília, a percepção muito evidenciada da mulher como um sujeito propenso desde o seu nascimento a dedicar-se às atividades relacionadas ao cuidado da casa, uma "ideologia naturalista, que empurra o gênero para o sexo biológico, reduz as práticas sociais a "papéis sociais" sexuados, os quais remetem ao destino natural da espécie" (KERGOAT, 2003, p.56, grifo da autora) e demonstra como a divisão sexual do trabalho é um dos aspectos da divisão social do trabalho.

Paralelamente, a dimensão precária dos trabalhos realizados por grande parte das entrevistadas é reforçada pelo desempenho das funções sem o registro em suas carteiras de trabalho, ou quando os tinha, os mesmos não correspondiam às atividades realizadas de fato. Para Hirata (2016, p.154) “o exemplo paradigmático do trabalho precário é o emprego doméstico, sobretudo o emprego de diarista, majoritariamente exercido sem vínculo empregatício, sem proteção social e sem direitos". Temos no conjunto das beneficiárias do PBF entrevistadas, uma parcela significativa desse exemplo:

\footnotetext{
Já trabalhei de olhar criança, cuidadora de criança. Trabalhei muito de faxina, de faxineira, só esses negócios mesmo, de doméstica, do lar. Tem muito tempo que eu estou parada, tem um ano. Eu nunca trabalhei fichada não, de carteira assinada mesmo, minha carteira é limpinha (Cecília, 38 anos, 4ạ série, beneficiária desde 2011).

Eu cuidava dos meninos, mas, eu também limpava o lugar. Minha carteira foi assinada como serviços gerais (Érica, 25 anos, ensino médio completo, beneficiária desde 2017).
}

Com a mesma expressividade do trabalho doméstico, temos experiências de trabalho como cuidadora de idosos, o qual, como aponta Hirata (2016, p.194), é exercido por mulheres 
cujas "as trajetórias de vida pontuadas pela pobreza, pelo desemprego e pela experiência do trabalho informal, sem proteção social e sem direitos, são uma constante que marca as trabalhadoras do cuidado nesse país". A experiência relatada a seguir, vai ao encontro da constatação da autora.

Depois eu casei e trabalhei de cuidadora de idosos um bom tempo, mas, não era fichado. Assim, ia e eles me pagavam para olhar no hospital. Foi assim, à noite de diarista mesmo, como é que eu posso te falar, assim, de auxiliar de serviços gerais, de cuidador de idosos, acompanhei. As pessoas pagavam particular. Mas minha carteira está assinada como serviços gerais (Virgínia, 33 anos, 8a série, beneficiária desde 2009).

Outra constatação, corrobora com Oliveira, Soares (2013) e Campello (2013) sobre o fato do PBF não contribuir para o desincentivo ao trabalho pelas beneficiárias. Grande parte das entrevistadas demonstra interesse por trabalhar, mas, a decisão por trabalhar, ou por continuar trabalhando, tem relação direta com as dificuldades vivenciadas por elas no âmbito privado do lar, onde as assimetrias de gênero são ainda muito presentes, "fala-se em igualdade de direito das mulheres, mas atribui-se a elas toda a extensão das tarefas [...] além das funções de procriação, cuidado e educação dos filhos, submissão ao marido [...]" (NICKNICH, 2016, p.237), como nas falas seguintes:

\footnotetext{
Minha vontade é de trabalhar, eu tenho vontade. Agora, meus filhos jamais eu deixo jogados para trabalhar (Virgínia, 33 anos, 8 a série, beneficiária desde 2009).

Eu trabalhei na padaria também, mas, não fiquei muito tempo porque não tinha ninguém para olhar os meninos. A minha menina morava com a minha mãe, ela veio morar comigo tem uns três anos. Então, não tinha ninguém para olhar, eu tive que sair do serviço. Como eu vou deixar os meninos sozinhos? Eu perco meus filhos (Filomena, 31 anos, beneficiária desde 2015).
}

Nessa medida, as implicações das relações entre o sexo, a raça e a classe, são recorrentes nas experiências de trabalho das beneficiárias do PBF deste estudo, as quais expõem um cenário desigual que limita o direito ao trabalho para as mesmas. Em suas experiências de trabalho, a grande maioria das beneficiárias relata a inserção em subempregos sem resguardo da legislação trabalhista e, em trabalhos com atividades tradicionalmente femininas, sobretudo, atividades relativas ao cuidado, o que mostra como a redução das práticas sociais a um destino natural, impulsiona a divisão sexual do trabalho.

\section{O PBF e as possibilidades de escolarização e de acesso ao trabalho pelas beneficiárias}


Quando analisada pela perspectiva dos benefícios não monetários via PBF, a pesquisa mostrou por meio das especificidades geracionais do grupo de beneficiárias estudado, que as potencialidades do Programa para que essas mulheres acessem o direito à educação e ao trabalho ainda é um ponto contencioso. A constatação de que quase a metade das beneficiárias $(41,66 \%)$ possuírem, na época das entrevistas mais de 40 anos, atrelado ao fato de estarem inseridas no Programa há um tempo considerável, reforça a argumentação de que "não haveria nesses programas nenhum amparo para que escolham se dedicar mais ao trabalho produtivo, gerador de independência e autonomia" (BARTHOLO; PASSOS; FONTOURA, 2017, p.11). Concomitantemente, os achados deste estudo corroboram com essas autoras quando argumentam que PBF não se atenta para a escolarização das mulheres adultas, igualmente pelas as singularidades vivenciadas por elas.

O estudo mostrou ainda, que mais da metade das beneficiárias está recebendo o benefício a mais de quatro anos, entretanto, com quase nenhum resultado de mobilidade social. Obviamente não descartamos os demais fatores que contribuem para um quadro de imobilismo social, mas, ainda assim, observamos que passados alguns anos de recebimento do benefício, não houve quase nenhuma alteração na realidade, tanto no campo educacional, quanto do fator trabalho na vida dessas mulheres beneficiárias do PBF em Ribeirão das Neves, MG. Destaca-se entre as entrevistadas, a beneficiária Nágela, que recebe benefícios sociais do Governo Federal desde o ano 2000, quando se cadastrou no Programa de Erradicação do Trabalho Infantil (PETI), pelo qual o benefício se dava via Bolsa Criança Cidadã, passando pelos demais programas sociais até se vincular ao PBF, no ano de 2003:

Eu comecei quando esse aí era pequeno, ele está com 21. Eu comecei no PETI, ele ficava lá e eu comecei a receber $\mathrm{R} \$ 40,00$, foi aumentando, aumentando, aumentando e colocou meus meninos todos, depois, agora, os meus netos (Nágela, 44 anos, analfabeta, beneficiária desde 2003).

No contexto do PBF, os programas complementares podem funcionar como possíveis meios para que os beneficiários acessem seus direitos. Como descreve Silva (2016) para além dos benefícios monetários, o PBF conta com ações e programas sociais que priorizam o acesso dos beneficiários, como o Brasil Alfabetizado, o Programa Nacional de Acesso ao Ensino Técnico e Emprego (PRONATEC), dentre outros. Contudo, como já relatado por meio das experiências de escolarização e de trabalho das beneficiárias, apenas duas mulheres 
concluíram o ensino médio, mas, não o fizeram na idade adequada por meio do ensino regular e nem por intermédio do PBF. Além disso, todas as beneficiárias estão fora do mercado de trabalho.

Nessa perspectiva, identificamos que uma das dificuldades do PBF no contexto de vida das entrevistadas é justamente possibilitar que a partir da inserção das mesmas no sistema de proteção social, o Programa se configure como uma possível porta de entrada para o acesso aos direitos à educação e ao trabalho. Esse limite do PBF no que concerne ao acesso a esses direitos, tem relação direta como a persistente condição de pobreza e insuficientes políticas públicas que prevalecem no munícipio, dentre elas a política de assistência social. Essa constatação é reforçada pelo fato do CRAS onde o estudo foi desenvolvido contar com uma equipe de trabalho reduzida, o que impossibilita até mesmo que o acompanhamento das condicionalidades do PBF seja realizado.

A limitação do PBF se dá ainda, por falta ou pouca interlocução das políticas públicas existentes, tanto no campo educacional, como de trabalho, e implica numa imobilidade social, a qual depende de multifatoriedade para ser modificada. Identificamos por meio das falas das entrevistadas, que as mesmas acessam apenas os benefícios monetários por meio do Programa. Como relatado pela coordenadora do CRAS onde as beneficiárias são referenciadas, a única interlocução com as ações complementares ao PBF ocorre por meio do PRONATEC, contudo:

Quando chega o PRONATEC, que o município vai ter cursos que sejam ofertados, a gente divulga. Nem sempre tem adesão, até mesmo porque os últimos que oferecidos, foram na região da BR-040. Foram dois cursos que aconteceram lá e para o nosso público ele vai ter o gasto do transporte, se ele não tem esse respaldo, fica complicado. Além do horário, porque esses eram noturnos. No caso a pessoa que é do lar, tem criança, dependendo da situação, as vezes à noite, nem sempre ela tem condições de sair de casa. Foi à noite, na BR, tinha essa questão do deslocamento. Os cursos do PRONATEC que são ofertados geralmente têm essas dificuldades. Vieram dois cursos, mas, as aulas iam acontecer do outro lado da BR, não me lembro o bairro, e não teve adesão no nosso território por esse motivo. Foi no final de 2017 e não veio mais. Inclusive os temas, porque esses cursos que vieram eu me lembro de que um era de Cervejeiro, o outro não me lembro. Eu acho que por mais que seja ofertado e o beneficiário do BF tenha prioridade, vai ter a possibilidade, mas, quando que isso realmente vai ser gerador de mudança na vida dessa pessoa? Quando ela vai ter a oportunidade de trabalhar com isso? (Josélia, coordenadora do CRAS).

O relato da coordenadora do CRAS nos remete a alguns pontos importantes, como a falta de recursos financeiros para que as beneficiárias se desloquem dentro do próprio município, bem como sobre a questão dos cursos serem ofertados somente nos bairros do 
outro lado da cidade. Além disso, o horário no qual o curso foi ofertado, como o próprio curso em si, "Cervejeiro", não nos parece o mais adequado para atender às demandas de qualificação da população do munícipio.

Ademais, como abordado ao longo deste estudo, reforçando as constatações de outros estudiosos, o PBF não trata de forma transparente as questões de gênero, mas, quando coloca como primazia que a mulher residente no domicílio seja a pessoa encarregada legal pelas famílias beneficiárias, aponta para essa mulher sua posição central no âmbito desse contexto. Entretanto, os relatos aqui expostos indicam que as especificidades dessas mulheres não são consideradas, pois as experiências das beneficiárias permanecem restritas apenas ao espaço privado do lar. Em sua grande maioria o benefício recebido via PBF está apenas cumprindo o papel de mantenedor de subsistência, o que não pode ser desconsiderado, pois é esse seu objetivo primeiro, mas, se mostra pouco expressivo no que se refere às ações e políticas complementares para o grupo estudado.

Nessa direção, o caminho para uma eventual oportunidade de se escolarizarem ou de trabalho, ainda é muito incipiente na vida das beneficiárias entrevistadas, especialmente porque suas experiências nos mostram que essas mulheres continuam tendo em diversas áreas de suas vidas seus direitos negados ou negligenciados. No entanto, acreditamos que o PBF representa o início de mudanças sociais de grande importância para milhares de brasileiros, e já mostrou que alinhado a outras políticas tem potencial para ser, principalmente para as beneficiárias, um meio pelo qual possam se reconhecerem como sujeitos de direitos.

\section{Considerações finais}

A partir de experiências de escolarização e de trabalho de beneficiárias do PBF do município de Ribeirão das Neves, em MG, este estudo evidenciou que as potencialidades que o PBF possui por meio das ações e programas complementares para que as beneficiárias acessem os direitos concernentes à educação e ao trabalho, são permeadas por grandes limites no território estudado.

Identificamos que mais da metade das beneficiárias entrevistadas estão inseridas no PBF há um tempo bastante considerável. Não obstante, continuam quase que sem mobilidade no que se refere à escolarização e ao trabalho. Nessa medida, consideramos que para as beneficiárias entrevistadas, o aprendizado via PBF tem pouca ou nenhuma representatividade 
para a construção de identidades e projetos de vida mais positivos para elas no que concerne à educação e ao trabalho.

Contudo, somos conscientes da existência da conjunção de fatores que leva a esse quadro de estagnação educacional e econômica das beneficiárias do PBF. Podemos enumerar dentre esses fatores, a imobilidade econômica do município, as inferências das relações de sexo, classe e raça, as quais funcionam como dificultadoras para que as beneficiárias acessem seus direitos, entre outros. E, é exatamente nesse sentido, que mesmo frente às limitações e dificuldades do PBF, acreditamos que o mesmo se apresenta para essas mulheres não só como uma forma de amenizar os impactos da pobreza, mas, como um Programa com grande potencial para que as beneficiárias acessem seus direitos no que concerne à educação e ao trabalho e amenizem as deformações sociais que perpassam suas vidas. Por sua característica de promoção e inclusão social, articulado a outras políticas, o PBF pode representar um importante meio pelo qual mulheres excluídas e socialmente vulneráveis possam acessar seus direitos. Especialmente, porque o PBF é a política de maior expressividade no âmbito da proteção social básica no município de Ribeirão das Neves.

Cientes do acirramento do desmonte do campo de direitos no Brasil, em que as políticas sociais como as do PBF têm sido ainda mais negligenciadas nos últimos anos, sendo aos poucos desmanteladas devido às perspectivas neoliberais vigentes, e que isso contribui ainda mais para o imobilismo social, onde as mulheres em condições de vulnerabilidade social devido às circunstâncias e dados já relatados neste estudo sentem profundamente os impactos negativos dessa omissão estatal, nos esforçamos e nos posicionamos para defender por meio da academia a importância do acesso ao direito à educação e ao trabalho pelas mulheres beneficiárias do PBF.

\section{Referências}

ARROYO, M.G. Educação de jovens-adultos: um campo de direitos e de responsabilidade pública. In: SOARES, L; GIOVANETTI, M. A. G. C.; GOMES, N. L. Diálogos na educação de jovens e adultos. Belo Horizonte: Autêntica, 2005. p.19-50.

BARDIN, L. Análise de conteúdo. São Paulo: Edições 70, 2011, p.9.

BARTHOLO, L.; PASSOS, L.; FONTOURA, N. Bolsa Família, autonomia feminina e equidade de gênero: o que indicam as pesquisas nacionais? Texto para discussão/ Instituto de Pesquisa Econômica Aplicada. Brasília: Rio de Janeiro, set. 2017.

BRASIL. Ministério da Cidadania (MC). Secretaria de Avaliação e Gestão da Informação 
- SAGI, 2019. Disponível em: https://aplicacoes.mds.gov.br/sagi/Rlv3/geral/relatorio. php\#Vis\%C3\%A3o\%20Geral\%20Brasil. Acesso em 02 jun. 2019.

- Ministério do Desenvolvimento Social e Combate à Fome (MDS). Secretaria de Avaliação e Gestão da Informação. Relatórios Gerenciais do Cadastro Único (RelCad), 2017. Disponível em:

https://aplicacoes.mds.gov.br/sagi/Rlv3/geral/relatorio.php\#Cadastro\%20\%C3\%9Anico. Acesso em 22 mai. 2018.

. Ministério do Desenvolvimento Social e Combate à Fome (MDS). Secretaria de Avaliação e Gestão da Informação. Relatório de Programas e Ações do MDS, 2018.

Secretaria de Avaliação e Gestão da Informação. Relatórios Gerenciais do Cadastro Único (RelCad), 2017.

2015, p.91-92. . Manual de gestão do Programa Bolsa Família. Brasília, 2. Ed,

. Decreto no 6.392, de 12 de março de 2008. Altera o Decreto no 5.209, de 17 de setembro de 2004, que regulamenta a Lei no 10.836, de 9 de janeiro de 2004 - Programa Bolsa Família. Brasília, DF: Presidência da República, 2008.

Política Nacional de Assistência Social - PNAS, aprovada pelo Conselho Nacional de Assistência Social por intermédio da Resolução no 145, de 15 de outubro de 2004, e publicada no Diário Oficial da União - DOU do dia 28 de outubro de 2004.

CAMARGO, C. F. et al. Perfil socioeconômico dos beneficiários do Programa Bolsa Família: o que o cadastro único revela? In: CAMPELLO, T; NERI, M C. Programa Bolsa Família: uma década de inclusão e cidadania. Brasília: Ipea, 2013. Cap. 9, p.157-176.

CAMPELLO, T. Uma década derrubando mitos e superando expectativas. In: CAMPELLO, Tereza; NERI, M C. Programa Bolsa Família: uma década de inclusão e cidadania. Brasília: Ipea, 2013. Cap. 1. p.15-24.

CARLOTO, C. M.; MARIANO S. A. Empoderamento, trabalho e cuidados: mulheres no programa bolsa família. Textos \& Contextos, Porto Alegre, v. 11, n. 2, p.258 - 272, ago./dez. 2012.

CHIZZOTI, A. Da pesquisa qualitativa. In: CHIZZOTI, A. Pesquisas em Ciências Humanas e Sociais. 3. ed. São Paulo: Cortez, 1998, p.78-105.

FALQUET, J. Transformações neoliberais do trabalho das mulheres: liberação ou novas formas de apropriação. In: ABREU, A R P.; HIRATA, H.; LOMBARDI, M R. Gênero e trabalho no Brasil e na França. 1. ed. São Paulo: Boitempo, 2016, p.37-46.

FRANÇA, V. H. Qualidade de vida da população em extrema pobreza de Ribeirão das Neves, região metropolitana de Belo Horizonte. 2016. 244f. Tese (Doutorado) - Centro de Pesquisas René Rachou, Programa de Pós-Graduação em Ciências da Saúde, Belo Horizonte. Disponível em: https://www.arca.fiocruz.br/handle/icict/15096. Acesso em 14 maio. 2018. 
GENTILI, P. Marchas y contramarchas. El derecho a laeducación y lasdinámicas de exclusiónincluyenteen América Latina (a sesentaaños de la Declaración Universal de los Derechos Humanos). Revista Iberoamericana de Educación. o 49, jan/abr, p.19-57, 2009.

HIRATA, H. O cuidado em domicílio na França e no Brasil. In: In: ABREU, Alice Rangeu de Paiva.; HIRATA, H.; LOMBARDI, M R. Gênero e trabalho no Brasil e na França. 1. ed. São Paulo: Boitempo, 2016, p.194-201.

. A precarização e a divisão internacional e sexual do trabalho. Sociologias, Porto Alegre, ano 11, n. 21, jan/jun, p. 24-41, 2009.

. Globalização e divisão sexual do trabalho. Cadernos Pagu, (17-18), p. 139-156,

2001.

INSTITUTO BRASILEIRO DE GEOGRAFIA E ESTATÍ́STICA (IBGE). IBGE Cidades, Ribeirão das Neves, 2017. Disponível em: https://cidades.ibge.gov.br/brasil/mg/ribeirao-dasneves/panorama. Acesso em 06 jan. 2018.

- Síntese de indicadores sociais: uma análise das condições de vida da população brasileira. Coordenação de População e Indicadores Sociais. - Rio de Janeiro: IBGE, 2017. 145p. Disponível em; https://biblioteca.ibge.gov.br/visualizacao/livros/liv101459.pdf. Acesso em: 13 jun. 2019.

LUDKE, M.; ANDRÉ, M. E. D. A. Abordagens qualitativas de pesquisa: a pesquisa etnográfica e o estudo de caso. In: LUDKE, M.; ANDRÉ, M. E. D. A. Pesquisa em Educação: abordagens qualitativas. São Paulo: Editora Pedagógica e Universitária, 1986. Cap. 2, p.11-24.

KERGOAT, D. Divisão sexual do trabalho e relações sociais de sexo. In: EMÍLIO, M.; TEIXERIA, M.; NOBRE, M.; GODINHO, T. Trabalho e cidadania ativa para as mulheres: desafios para as Políticas Públicas. São Paulo, 2003, p.55-64.

A propósito de las relacines sociales de sexo. In: KERGOAT, D; HIRATA, H.; ZYLBERBERG-HOCQUARD M.H. La division sexual del trabalho: permanencia y cambio. 1. ed. Argentina: Asociacion Trabajo y Sociedad, 1997, p.31-39.

MINAYO, M. C. S. Ciência, técnica e arte: o desafio da pesquisa social. In: MINAYO, M. C. S.; DESLANDES, S. F.; GOMES, R. (orgs). Pesquisa social: teoria, método e criatividade. 21. ed. Petrópolis, RJ: Vozes Limitada, 2002. Cap.1, p.9-21.

NICKNICH, M. As relações de gênero no contexto do direito social ao trabalho: reflexões acerca da discriminação e da desigualdade. In: NICKNICH, M. Direito, Trabalho e Mulher: diálogos como princípio da fraternidade. 1.ed. Rio de Janeiro: Lumen Juris, 2016. Cap. 3, p.191-289.

OLIVEIRA, L. F. B.; SOARES, S. S. D. Bolsa Família e Repetência: resultados a partir do CadÚnico, projeto frequência e censo escolar. In: CAMPELLO, T.; NERI, M.C. Programa Bolsa Família: uma década de inclusão e cidadania. Brasília: Ipea, 2013. Cap. 18, p.285-296. 
REGO, W. L; PINZANI, A. Vozes do Bolsa Família: autonomia, dinheiro e cidadania. 1.ed. São Paulo: Unesp, 2013. 241p.

ROSEMBERG, F. Mulheres educadas e a educação das mulheres. In: PINSKY, C B.; PEDRO, J M. Nova história das mulheres no Brasil. 1.ed. São Paulo: Contexto, 2013, p.333-481.

SANTOS, Yumi Garcia dos. As mulheres como pilar da construção dos programas sociais. Cad. CRH, 2014, vol.27, n.72, p.483. Disponível em http://www.scielo.br/pdf/ccrh/v27n72/03.pdf. Acesso em: 23 mar. 2018.

SAVIANI, D. Pedagogia histórico-crítica: primeiras aproximações. In: SAVIANI, D. Sobre a Natureza e Especificidade da Educação. 11. ed. Campinas: Autores Associados, 2011, p.1121.

SILVA, M.O.S.; LIMA, V. F. S. A. Antecedentes e Contextualização: trajetória de desenvolvimento do Bolsa Família. In: SILVA, M. O. S. O Bolsa Família: verso e reverso. 1. ed. Papel Social, 2016. Cap.1, p.21-38.

Caracterizando o Bolsa Família: uma aproximação ao processo de unificação dos programas de transferência de renda no Brasil. In: SILVA, M O S. Avaliando o Bolsa Família: unificação, focalização e impactos. 1. ed. São Paulo: Cortez, 2010, p.33-62.

SILVA, O. H. R. Segregação espacial na Região Metropolitana de Belo Horizonte: o caso de Ribeirão das Neves, Minas Gerais. 2016. 99f. Dissertação (Mestrado em Arquitetura e Urbanismo) - Universidade Federal de Viçosa. Programa de Pós-Graduação em Arquitetura e Urbanismo, Viçosa. Disponível em: http://www.locus.ufv.br/handle/123456789/8217. Acesso em 03 mar. 2018.

SOARES, S.; SÁTYRO, N. O Programa Bolsa Família: Desenho institucional e possibilidades futuras. In: CASTRO, J. A; MODESTO, L. Bolsa Família 2003-2010: avanços e desafios. 1. ed. Brasília: Ipea, 2010. Cap. 5, p.27-55. 